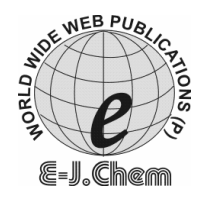

http://www.e-journals.net
ISSN: 0973-4945; CODEN ECJHAO

E-Journal of Chemistry 2010, 7(3), 1040-1044

\title{
Synthesis and Antifungal Activity of 2-Ketophenyl-3-substituted aryl-1-thiazolidin-4-ones
}

\author{
VISHNU VATS ${ }^{*}$, R. K. UPADHYAY and PRATHIBHA SHARMA ${ }^{\S}$ \\ Department of Chemistry, \\ N.R.E.C.College, Chaudhary Charan Singh University, Meerut, India. \\ ${ }^{\S}$ Department of Plant Pathology, \\ Indian Agricultural Research Institute, New Delhi, India.
}

vatsvish_2006@yahoo.co.in

Received 5 September 2009; Revised 11 November 2009; Accepted 5 January 2010

\begin{abstract}
A new series of 2-ketophenyl-3-substituted aryl-1- thiazolidin-4ones were synthesized by cyclocondensation of ketoazomethines and thioglycolic acid. Ketoazomethines were synthesized by condensation of phenyl glyoxal (prepared by partial oxidation of acetophenone) and various para-substituted anilines. Their structures were elucidated by elemental analysis, IR and $\mathrm{H}^{1} \mathrm{NMR}$; they were screened for their antifungal activity against hazardous fungi namely Fusarium Oxysporum, Pythium, Sclerotium and Alternaria brassicola.
\end{abstract}

Keywords: Synthesis, 2-Ketophenyl-3-substituted aryl-1-thiazolidin-4-ones, Antifungal activity.

\section{Introduction}

4-Thiazolidinones are most popular, probably owing to their high versatility in exhibiting diverse potent biological properties viz., antiprotozoa ${ }^{1}$, analgesic ${ }^{2-5}$, anti-inflammatory ${ }^{6-9}$ anti$\mathrm{HIV}^{10}$, CFTR-inhibitor ${ }^{11}$, anticonvulsant ${ }^{12-13}$, SHP-inhibitor ${ }^{14}$, antimicrobial ${ }^{15,16}$ and fungicidal ${ }^{17}$ etc. Although plenty of thiazolidinones and their derivatives have been synthesized by condensation of Schiff bases ${ }^{18-20}$, halo acetanilide ${ }^{21}$, thiosemicarbazone ${ }^{22}$, thiamide ${ }^{23}$, with thiocyanates, halo fatty acid and aldehydes etc. This project includes synthesis of these compounds and their elemental, spectral studies and screening for antifungal activity against hazardous fungi i.e. Fusarium Oxysporum, Alternaria Brasssicola, Sclerotium and Pythium which cause harm to crops like tomato, onion and cauliflower.

\section{Experimental}

All the chemicals used were either E-Merck or Qualigens. Melting points of all the compounds determined in open glass capillaries were uncorrected. Elemental analysis of 
samples was carried out on Euro EA Elemental Analyzer. Infrared spectra were recorded in $\mathrm{KBr}$ medium on Thermo Nicolet Nexus FT-IR spectrophotometer and $300 \mathrm{MHz}$ NMR spectra were recorded in dimethylsulphoxide medium on Varian C-13 NMR spectrometer using TMS as internal standard. Column chromatography was carried out using silica gel (finer than 200\#).Characterization data is presented in Table 1 and spectral data in Table 2.

Table 1. Characterization data of compounds (6a-f).

\begin{tabular}{|c|c|c|c|c|c|c|c|c|}
\hline \multirow[t]{2}{*}{ Compds } & \multirow[t]{2}{*}{ M.F. } & \multirow{2}{*}{ Colour } & \multirow{2}{*}{$\begin{array}{l}\text { Yield } \\
\%\end{array}$} & \multirow{2}{*}{${ }^{\mathrm{m} . \mathrm{p} .}$} & \multicolumn{4}{|c|}{ Elemental analysis, \% Cald.(found) } \\
\hline & & & & & $\mathrm{S}$ & $\mathrm{C}$ & $\mathrm{H}$ & $\mathrm{N}$ \\
\hline $6 a$ & $\mathrm{C}_{16} \mathrm{H}_{12} \mathrm{NO}_{2} \mathrm{SCl}$ & Pink & 67.4 & 223 & $\begin{array}{c}7.6 \\
(7.8)\end{array}$ & $\begin{array}{c}60.37 \\
(60.44)\end{array}$ & $\begin{array}{c}3.77 \\
(3.18)\end{array}$ & $\begin{array}{c}4.40 \\
(4.76)\end{array}$ \\
\hline $6 b$ & $\mathrm{C}_{16} \mathrm{H}_{12} \mathrm{NO}_{2} \mathrm{SBr}$ & Yellow & 78.5 & 245 & $\begin{array}{c}9.2 \\
(9.1)\end{array}$ & $\begin{array}{c}53.35 \\
(53.39)\end{array}$ & $\begin{array}{c}3.31 \\
(3.35)\end{array}$ & $\begin{array}{c}3.86 \\
(3.15)\end{array}$ \\
\hline $6 c$ & $\mathrm{C}_{20} \mathrm{H}_{22} \mathrm{~N}_{2} \mathrm{O}_{2} \mathrm{~S}$ & $\begin{array}{l}\text { Light } \\
\text { brown }\end{array}$ & 63.6 & 235 & $\begin{array}{c}8.0 \\
(7.8)\end{array}$ & $\begin{array}{c}67.79 \\
(67.83)\end{array}$ & $\begin{array}{c}6.21 \\
(6.35)\end{array}$ & $\begin{array}{c}7.90 \\
(7.65)\end{array}$ \\
\hline 6d & $\mathrm{C}_{17} \mathrm{H}_{15} \mathrm{NO}_{2} \mathrm{~S}$ & Bro & 71.5 & 218 & $\begin{array}{c}8.9 \\
(9.1)\end{array}$ & $\begin{array}{c}68.68 \\
(68.65)\end{array}$ & $\begin{array}{c}5.75 \\
(5.86)\end{array}$ & $\begin{array}{c}4.71 \\
(4.23)\end{array}$ \\
\hline $6 e$ & $\mathrm{C}_{16} \mathrm{H}_{12} \mathrm{~N}_{2} \mathrm{O}_{4} \mathrm{~S}$ & $\begin{array}{l}\text { Light } \\
\text { green }\end{array}$ & 65.6 & 228 & $\begin{array}{c}8.6 \\
(8.5)\end{array}$ & $\begin{array}{c}58.53 \\
(58.74)\end{array}$ & $\begin{array}{c}3.65 \\
(3.46)\end{array}$ & $\begin{array}{c}8.53 \\
(8.32)\end{array}$ \\
\hline 6d & $\mathrm{C}_{16} \mathrm{H}_{13} \mathrm{NO}_{2} \mathrm{~S}$ & Orange & 69.5 & 210 & $\begin{array}{c}8.3 \\
(8.4)\end{array}$ & $\begin{array}{c}67.84 \\
(67.73)\end{array}$ & $\begin{array}{c}4.59 \\
(4.13)\end{array}$ & $\begin{array}{c}4.96 \\
(4.12)\end{array}$ \\
\hline
\end{tabular}

Table 2. IR, $\mathrm{H}^{1} \mathrm{NMR}$ Spectral data of the compounds (6a-f).

\begin{tabular}{cll}
\hline Compds. & \multicolumn{1}{c}{$\mathrm{IR}, \mathrm{cm}^{-1}(\mathrm{KBr})$} & \multicolumn{1}{c}{$\mathrm{H}^{1} \mathrm{NMR}(\delta \mathrm{ppm})$} \\
\hline $\mathbf{6 a}$ & $560,700,750,818$, & $7.48-7.50(6 \mathrm{H}, \mathrm{m}), 6.89(4 \mathrm{H}, \mathrm{m})$, \\
& $1241,1324,1486$, & $5.11(1 \mathrm{H}, \mathrm{s}), 3.98(2 \mathrm{H}, \mathrm{s})$ \\
\multirow{2}{*}{ 6b } & $1542,1605,1651,3061$ & \\
& $660,752,822,1326$, & $7.51-7.72(6 \mathrm{H}, \mathrm{m}), 6.78(4 \mathrm{H}, \mathrm{m})$, \\
6c & $1489,1549,1609,1648,3066$ & $5.15(1 \mathrm{H}, \mathrm{s}), 3.82(2 \mathrm{H}, \mathrm{s})$ \\
& $692,778,1407,1594,1680,1684$, & $7.56-7.73(6 \mathrm{H}, \mathrm{m}), 7.11(2 \mathrm{H}, \mathrm{d}) 6.92(2 \mathrm{H}, \mathrm{d})$, \\
6d & 2970,3032 & $3.89(2 \mathrm{H}, \mathrm{s}), 2.75(3 \mathrm{H}, \mathrm{m}), 5.21(1 \mathrm{H}, \mathrm{s})$ \\
& $694,756,1238,1316,1496,1543$, & $7.48-7.51(6 \mathrm{H}, \mathrm{m}), 4.02(2 \mathrm{H}, \mathrm{s}), 4.31(2 \mathrm{H}, \mathrm{s})$, \\
6e & $1595,1670,3052$ & $2.75\left(3 \mathrm{H}, \mathrm{s}, \mathrm{Ar}-\mathrm{CH}_{3}\right), 5.43(1 \mathrm{H}, \mathrm{s})$ \\
& $683,771,888,1286,1569,1652$, & $7.33-7.36(6 \mathrm{H}, \mathrm{m})$, \\
6f & 1713,3045 & $4.05(2 \mathrm{H}, \mathrm{S}), 4.28(2 \mathrm{H}, \mathrm{s}), 5.34(1 \mathrm{H}, \mathrm{s})$ \\
& $648,700,748,813,1257,1458$, & $7.35-7.54(5 \mathrm{H}, \mathrm{m}), 7.51-$ \\
& $1515,1682,1726,3056$ & $7.64(4 \mathrm{H}, \mathrm{m}), 4.25(2 \mathrm{H}, \mathrm{s}), 5.32(1 \mathrm{H}, \mathrm{s})$ \\
\hline
\end{tabular}

Preparation of phenyl glyoxal

Phenyl glyoxal was prepared by the partial oxidation of acetophenone with selenium dioxide. Reaction mixture containing acetophenone (1,0.2 mol) and selenium dioxide $(0.4 \mathrm{~mol})$ was taken in a round bottom flask containing $300 \mathrm{~mL}$ of $95 \%$ ethyl alcohol and refluxed for 4-6 h. Orange yellow reaction mixture was decanted and concentrated over water bath and dissolved in ether to remove selenium from the product.

\section{General procedure for preparation of 4- thiazolidinones}

Preparation of ketoazomethines (4a-f)

Phenyl glyoxal (2, $0.2 \mathrm{~mol})$ and aniline (3a-f, $0.2 \mathrm{~mol})$ were taken in a round bottom flask containing $100 \mathrm{~mL}$ of ethanol and refluxed on water bath for $8 \mathrm{~h}$. Excess of ethanol was 
removed from reaction mixture and cooled at room temperature. Then it was poured in ice cold water and filtered. Solid obtained were collected and recrystallized with ethanol. Similarly, other ketoazomethines of $p$-chloro, $p$-bromo, $p$-nitro, $p$-methyl and $p$-diethylaminoaniline were prepared.

\section{Preparation of 2-ketophenyl-3-substituted aryl-1-thiazolidin-4-one (6a-f)}

Ketoazomethines ( $0.2 \mathrm{~mol}, \mathbf{4 a - f})$ and thioglycolic acid $(0.3 \mathrm{~mol}, 5)$ were refluxed in dry benzene for $\sim 15 \mathrm{~h}$. The reaction mixture was concentrated to half of its volume over water bath and then neutralized with sodium bicarbonate solution. The contents were cooled and poured in ice cold water and filtered. The solid obtained was collected and purified by recrystallization (Scheme 1).

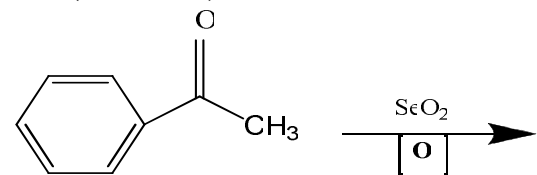

(1)

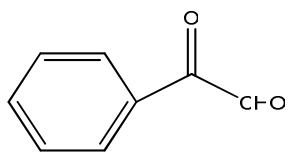

(2)

$+$

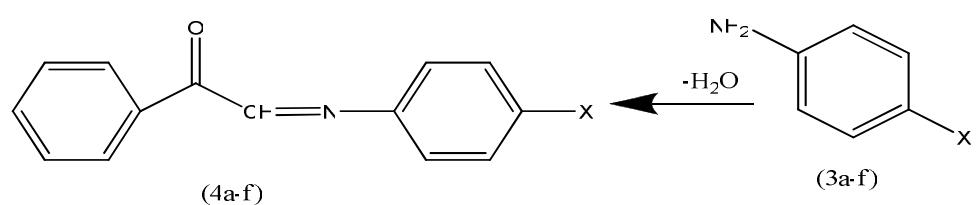

3a: $p$-Chloroaniline

3b: $p$-Bromoaniline

3c: $p$-Diethylaminoaniline

3d: $p$-Methylaniline

3e: $p$-Nitroaniline

3f: Aniline

(5)

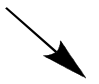

Scheme I

\section{Antifungal activities}

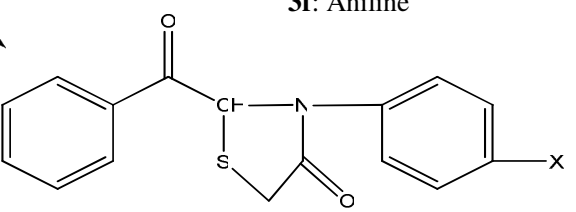

(6a-f)

\section{Preparation of medium and sample solutions}

For the preparation of PDA (Potato Dextrose Agar) medium 250 g potato pieces boiled in water were filtered and filtrate was made up to 1 litre. To this solution $20 \mathrm{~g}$ dextrose powder was added followed by heating to a syrupy viscous consistency. Standard solutions of all the samples were prepared by dissolving known quantity of compounds in known volume of DMSO (dimethylsulphoxide).

The synthesized thiazolidinones were screened for their antifungal activity against hazardous fungi namely Fusarium Oxysporum, Pythium, Alternaria brassicola and Sclerotium by paper disc method ${ }^{24}$ using Diethane-M45 as reference fungicide and DMSO as control showing no inhibition, incubation periods of $72 \mathrm{~h}$ at $25-30{ }^{\circ} \mathrm{C}$ for the growth of fungi were measured in triplicates and the results of inhibition were noted in Table 3. 
Table 3. Antifungal activity of 2-ketophenyl-3-substituted aryl-1-thiazolidin-4-one.

\begin{tabular}{ccccccc}
\hline Compound & M.F. & $\begin{array}{c}\text { Incb. Time, } \\
\text { days }\end{array}$ & S. & P. & F.O. & A.B. \\
\hline $\mathbf{6 a}$ & $\mathrm{C}_{16} \mathrm{H}_{12} \mathrm{NO}_{2} \mathrm{SCl}$ & 3 & ++ & ++ & + & ++ \\
$\mathbf{6 b}$ & $\mathrm{C}_{16} \mathrm{H}_{12} \mathrm{NO}_{2} \mathrm{SBr}$ & 3 & ++ & ++ & ++ & ++ \\
$\mathbf{6 c}$ & $\mathrm{C}_{20} \mathrm{H}_{22} \mathrm{~N}_{2} \mathrm{O}_{2} \mathrm{~S}$ & 3 & - & + & - & - \\
$\mathbf{6 d}$ & $\mathrm{C}_{17} \mathrm{H}_{15} \mathrm{NO}_{2} \mathrm{~S}$ & 3 & - & + & - & + \\
$\mathbf{6 e}$ & $\mathrm{C}_{16} \mathrm{H}_{22} \mathrm{~N}_{2} \mathrm{O}_{4} \mathrm{~S}$ & 3 & ++ & - & - & + \\
6f & $\mathrm{C}_{16} \mathrm{H}_{13} \mathrm{NO}_{2} \mathrm{~S}$ & 3 & ++ & - & - & ++ \\
Ref. & Diethane-M45 & 3 & + & ++ & - & ++ \\
\hline
\end{tabular}

Sample $10 \mathrm{mg} / \mathrm{mL}$, S.-Sclerotium, P.-Pythium, F.O.-Fusarium Oxysporum, A.B - Alternaria Brasssicola $-v e=1-7 \mathrm{~mm},+v e=10-15 \mathrm{~mm}$ and $++v e=15-18 \mathrm{~mm}$.

\section{Results and Discussion}

The antifungal studies of the compounds were tested by paper bit method against hazardous fungi namely Fusarium Oxysporum, Alternaria Brassicola, Pythium and Sclerotium and were compared with reference fungicidal Diethane-M45, 2-ketophenyl-3-(4-bromoaryl)-1thiazoldin-4-one (6b) and 2-ketophenyl-3-(4-chloroaryl)-1-thiazolidin-4-one (6a) showed highest inhibition against Fusarium Oxysporum, Alternaria Brassicola, Sclerotium and Pythium. 2-ketophenyl-3-(4-nitroaryl)-1-thiazolidin-4-one (6e) showed highest inhibition against Sclerotium, 2-ketophenyl-3-aryl-1-thiazolidin-4-one (6f) was effective against Alternaria brassicola and Sclerotium. Therefore, from the results it is evident that compounds having electronegative groups are responsible for antifungal activity.

\section{Acknowledgment}

We are grateful to Mrs. Prathibha Sharma (Principal Scientist) and the staff of Plant Pathology department of Indian Agricultural Research Institute, New Delhi and staff of IIT Roorkee for their immense support.

\section{References}

1. Tenorio R P, Carvalho C S, Pessanha C S, Lima J G, Faria A R, Alves A J, Melo E J T and Goes A J S, Bioorg Med Chem Lett., 2005, 15, 2575.

2. Kucukguzel G, Oruc E E, Rollas S, Ahin F and Qzbet A, Eur J Med Chem., 2002, 37, 197.

3. Vigorta M G, Ottana R, Môn forte F, Maccari R, Trovato A, Môn forte M T and. Taviano M F, Bioorg Med Chem Lett., 2001, 11, 2791.

4. Khamees H A A, Boyomi S M, Kandil H A and Tahir K E H E, Eur J Med Chem., 1990, 25, 103.

5. Ralkan A, Goren Z, Urgun H, Calts U, Cakar A.N, Atilla P and Uzbay T, ArzneimForsch/Drug Res., 2002, 52, 462.

6. Goel B, Ram T, Tyagi R, Bansal E, Kumar A, Mukherjee D and Sinha J N, Eur J Med Chem., 1999, 34, 265.

7. Taddei A, Folli C, Moran O Z, Fanen P, Verkmen A S and Galietta L T V, FEBS Lett., 2004, 558, 52.

8. Upadhyay R K, Agarwal N and Gupta N, J Indian Chem Soc., 1993,70, 537.

9. Bonde C G and Gaikwad N J, J Bioorg Med Chem., 2004, 12, 2151.

10. Rao A, Balzarini J, Carbone A, Chimirri A, Declereq A, Monforte A M, Monforte P, Pannecouque C and Zappala M, Antiviral Res., 2004, 63, 79. 
11. Gargi, Synthesis, Characterization and Biological Activities of Ketoanils, Ph.D. Thesis, Meerut University, Meerut, India, 2000.

12. Sun Q, Tafesse L, Limberis $\mathbf{J} \mathrm{T}$ and Islam K, J Comb Chem High Throughput Screening, 2003, 6, 481.

13. Lakhan R and Singh R L, J Agri Food Chem., 1991, 39, 580.

14. Geronikaki A, Eleftheriou P, Vicini P and Alam I, J Med Chem., 2008, 51(17), 5221.

15. Panwar H, Verma R S, Srivastava V, Kumar A, Indian J Chem., 2006, 45B, 2088.

16. Ali T E S, Phosphorous, Sulfur, Silicon Relat Elem., 2007, 182, 1717.

17. Patel J A, Mistry B D and Desai K R, J Indian Chem Soc., 2006, 83, 1041.

18. Niyogi B G and Ghosh D, J Indian Chem Soc., 2004, 81, 22.

19. Mehta K J, Chawala A C and Parikh A R, J Indian Chem Soc., 1979, 56, 173.

20. Kamdar G C, Bhatt D J and Parikh A R, Acta Cienc Indica (Ser Chem), 1982, 8, 134.

21. Dopardo and Robert M, Synthesis, 1981, 10, 825.

22. Smolanka I V, Man'o N P and Krasnatskaya A T, Khim Geteratsika Soedin, 1981, 5, 627.

23. Bhargava P N, Shree P and Ram L, J Indian Chem Soc., 1981, 58, 927.

24. Baur A W, Kirby M, Csherris J and Turk M, Am J Clin Pathol., 1966, 45, 493. 


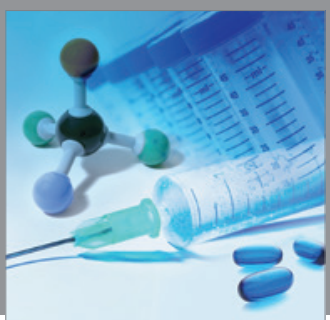

International Journal of

Medicinal Chemistry

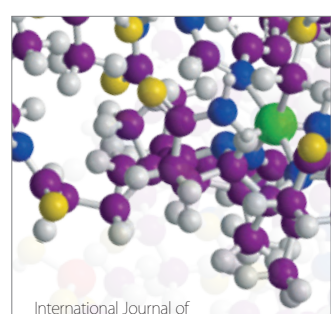

Carbohydrate Chemistry

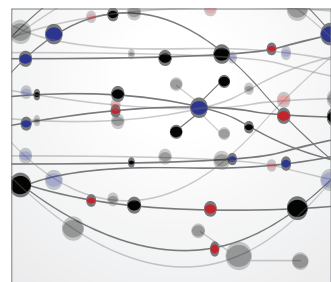

The Scientific World Journal
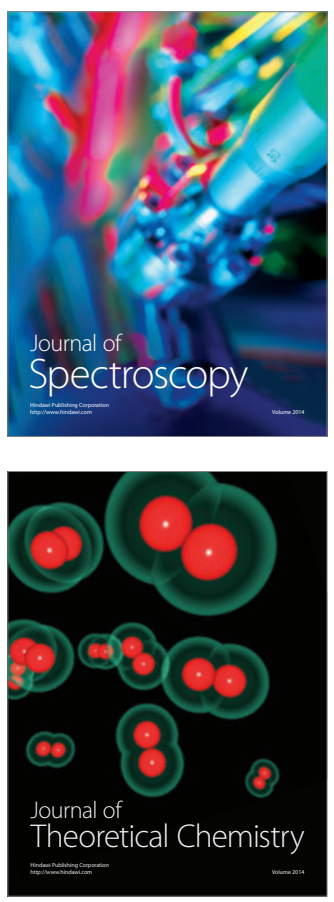
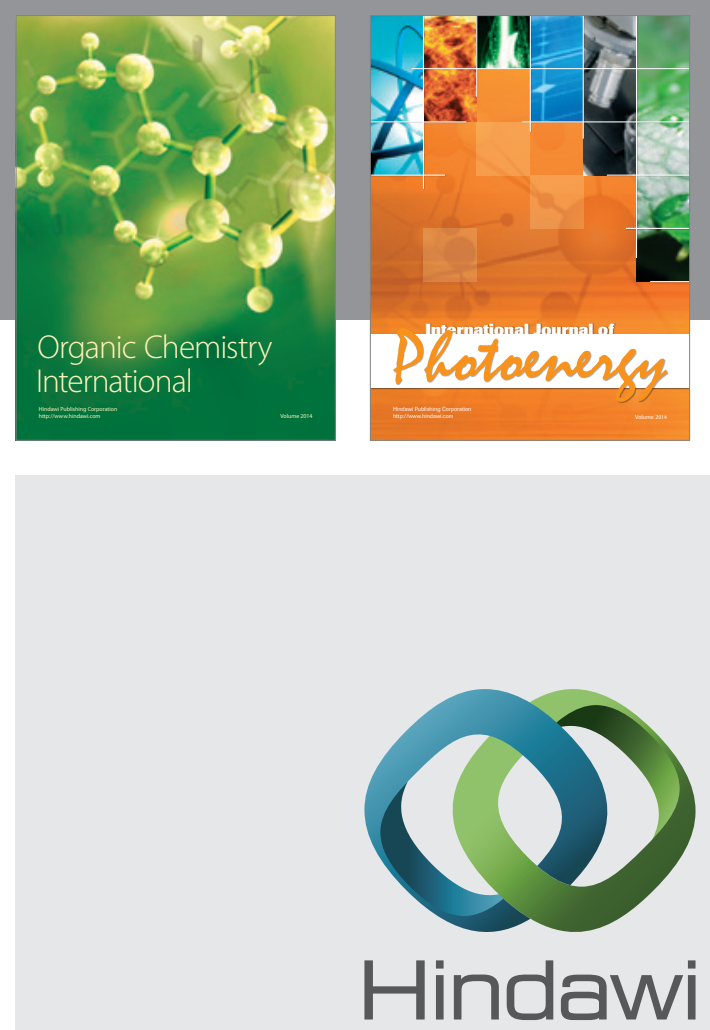

Submit your manuscripts at

http://www.hindawi.com
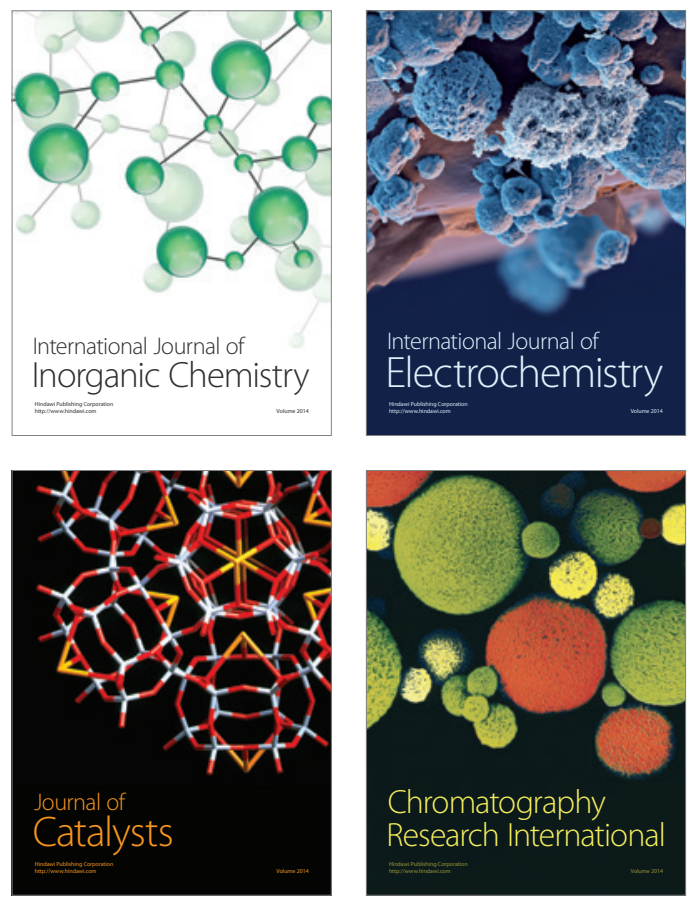
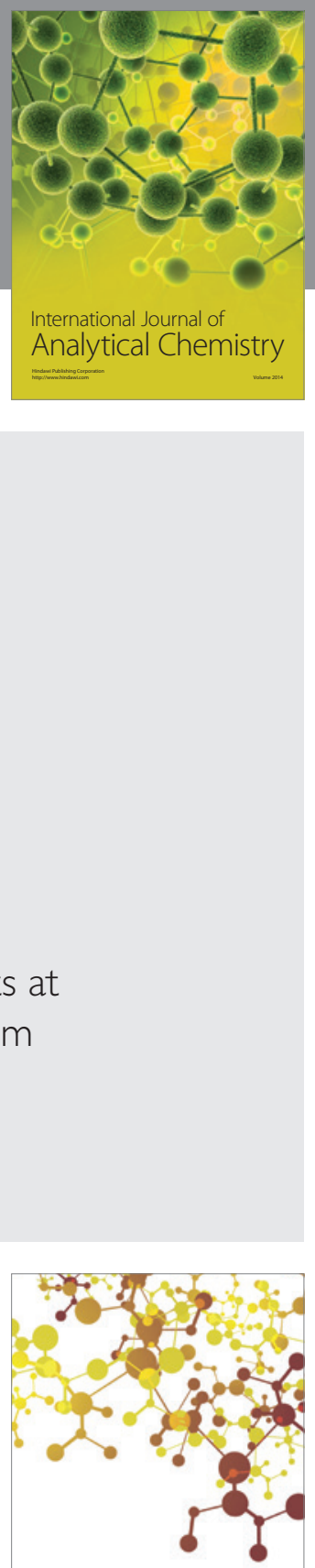

Journal of

Applied Chemistry
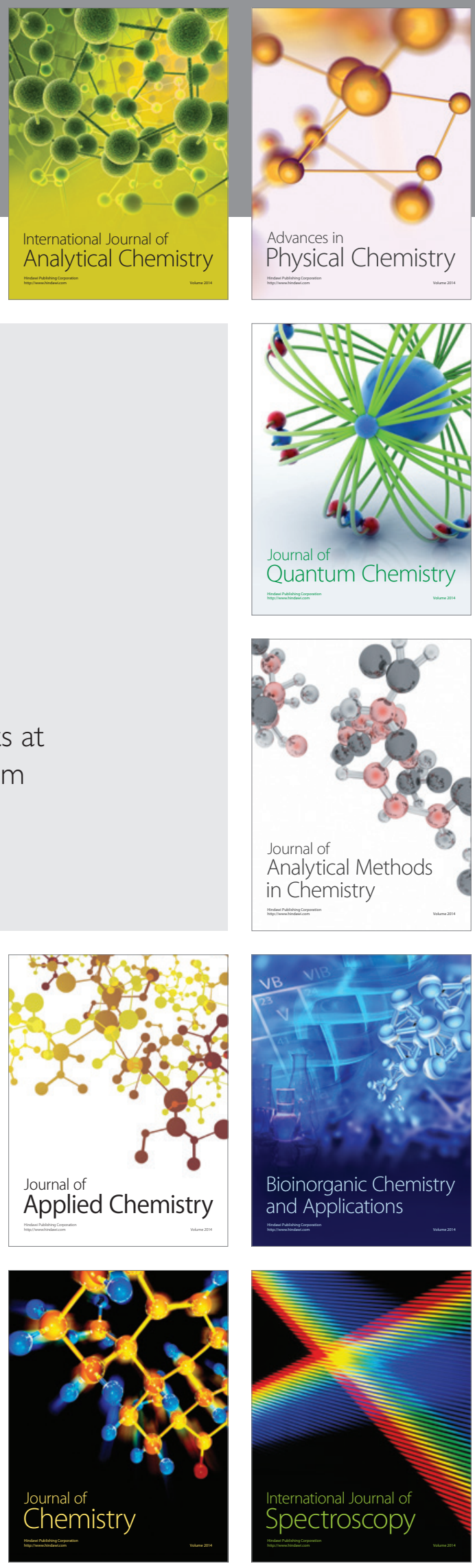